\title{
National Action Plan on Antimicrobial Resistance: stakeholder analysis of implementation in Ghana
}

\author{
Tamara Jimah $^{1}$ (D), Oladele Ogunseitan ${ }^{1}$ (D) \\ 1 Department of Population Health \& Disease Prevention, University of California, Irvine, California, USA \\ Keywords: antimicrobial resistance, ghana, policy, national action plan \\ https://doi.org/10.29392/001c.13695
}

\section{Journal of Global Health Reports}

Vol. 4, 2020

\begin{abstract}
Background
Understanding potential barriers to implementation of public health policy is important to ensure well-informed decisions, and stakeholders play critical roles in implementation. Stakeholder analysis is expected to shed light on Ghana's progress with the implementation of the National Action Plan on Antimicrobial Resistance since the completion of the Global Health Security Agenda's Joint External Evaluation. The outcome of stakeholder analysis can improve understanding of their roles and institutional capacity to promote prudent use of antibiotics in populations at the community level.
\end{abstract}

\section{Methods}

Eight semi-structured in-depth interviews were conducted with participants of the Joint External Evaluation process, including personnel from the policy, research, and practice programs in Ghana's public health sector. In-person interviews were conducted between September and October 2018 in the Greater Accra and Upper West regions.

\section{Results}

The analysis revealed four main themes: national burden of disease and antibiotic resistance, policy development, implementation barriers, and strategies. Ghana's national antimicrobial policy and action plans to enhance public education and awareness align with the objectives of the Global Action Plan on Antimicrobial Resistance. All respondents expressed concern about the increasing proliferation of antibiotic-resistant bacteria, which they attribute in part to the inappropriate use of antibiotics in local communities. Although Ghana has laws to regulate the sale of antibiotics, enforcement has been a major challenge. Inadequate funding for monitoring compliance comprises the greatest challenge. Stakeholders also acknowledged the importance of strengthening cross-sectoral collaboration, and the need to leverage resources from the animal and environmental sectors through a One Health approach to ensure successful implementation of the national action plan.

\section{Conclusions}

This study identified several opportunities for effective implementation of the Ghana's National Action Plan on Antimicrobial Resistance. Stakeholders were enthusiastic about the effectiveness of the One Health approach, and there is strong political will to promote multisectoral partnership to advance implementation efforts.

The resistance of deadly pathogens to antibiotics is a major concern for global health, particularly in Africa where there is a high prevalence of antibiotic prescriptions. ${ }^{1-4}$ The dire consequences of increasing morbidity and mortality attributed to antibiotic resistance led to the development of the Global Action Plan (GAP), and subsequent National Action Plans (NAP) to combat antimicrobial resistance (AMR) across the globe. ${ }^{3,5}$ The development of the NAP was preceded by the completion of the Joint External Evaluation (JEE) under the Global Health Security Agenda, a voluntary evaluation conducted by a multisectoral team to examine countries' capacity to prevent, detect, and respond to public health threats. 6,7 The JEE is made up of nineteen technical areas that are further divided into specific indicators and measured on a scale of 1 to 5, representing the lowest and highest scores, respectively, in terms of national capacity for a given indicator. Results from Ghana's JEE report revealed several gaps in the country's capacity to address AMR, a common finding in the WHO Africa Region. ${ }^{8-10}$ The Government of Ghana is committed to mitigating the 
threats of antibiotic resistance and has taken several steps in policy development to address these gaps, as illustrated in Figure 1. For example, a year after the completion of the JEE, the National Policy on Antimicrobial Use and Resistance $^{11}$ and an accompanying five-year NAP ${ }^{12}$ were endorsed by the president of Ghana. The policy and plan were developed in alignment with the objectives of the GAP. ${ }^{3}$

The NAP is composed of five strategic objectives, with each having a corresponding budget allocation. The first strategic objective, and the focus of this study, relates to improving awareness and understanding of antimicrobial resistance through effective communication, education and training. ${ }^{12}$ It proposes to enhance collaboration with diverse stakeholders, including civil organizations and the media, to promote responsible use of antimicrobials among the general public. ${ }^{12}$ A major strength of the NAP is that it was developed on the One Health $(\mathrm{OH})$ approach, and involved a collaborative effort of stakeholders from multiple disciplines in the human, environment, and animal sectors. ${ }^{13-15}$ Zoonotic and environmental pathogens have caused dire health consequence to human populations. The overuse of antibiotics as prophylactics in animal husbandry complicates the problem of antibiotic resistance as resistant bacteria can be transmitted from animals to humans through contaminated food and unsafe handling of sick animals, ${ }^{16,17}$ thus reiterating the necessity of the $\mathrm{OH}$ approach. With an estimated $75 \%$ of emerging infectious diseases, including COVID-19 and Ebola hemorrhagic fever, linked to animal reservoirs, the complexity of current global health problems calls for multidisciplinary action. ${ }^{18-20}$ Moreover, in low-resource settings with a confluence of biological risk factors and entrenched social determinants, the failure of preventive strategies means difficult and expensive responses to curb the spread of diseases.

There is a high prevalence of multidrug-resistant bacteria in Ghana. ${ }^{21}$ For instance, results from a nationwide study of eleven hospitals revealed high rates of over $70 \%$ resistance among pathogenic bacterial isolates observed for Ampicillin, Chloramphenicol, Cotrimoxazole, and Tetracycline. $^{21}$ This poses great concern given that some of the aforementioned antibiotics are used in the treatment of serious infections, including meningitis, tuberculosis, diarrheal and respiratory infections which rank among the country's top contributors to disability adjusted life years (DALYs). ${ }^{22}$ Lack of awareness about antibiotic resistance has led to the inappropriate use of antibiotics in the general population. Studies have reported an association between sociodemographic factors and antibiotic use, highlighting the need for appropriate interventions to increase health literacy in communities. For instance, differences have been observed in knowledge and use of antibiotics by gender, age, and education. ${ }^{23-25}$ Education, for example, has been found to be an important predictor of health knowledge and behavior. ${ }^{26,27}$ Informal sale of antibiotics by unqualified personnel also contributes to antibiotic misuse in communities, despite laws prohibiting such practice. ${ }^{9,16}$ Recognizing these existing gaps in public knowledge subsequently informed the formulation of the first strategic objective of the NAP. ${ }^{11,12}$

Given the instrumental role of stakeholders in ensuring effective implementation of the NAP, this study aimed to better understand key stakeholders' perspectives about Ghana's plans to address antibiotic resistance and the ongoing efforts to strengthen collaboration for effective implementation of the first strategic objective, specifically those related to promoting prudent use of antibiotics in communities. Therefore, our study focused on stakeholders from the human health sector, including the role of individuals in the implementation and sustainability of public health interventions. ${ }^{28,29}$

\section{METHODS}

\section{RESPONSIBLE CONDUCT OF RESEARCH AND ETHICS}

Approval of human participants in this research was obtained from the Ethics Committee of the Institute of Statistical, Social, and Economic Research at the University of Ghana, Legon (ECH \# 106/17-18), and the Institutional Review Board of the University of California, Irvine (HS\# 2018-4325). Participation was voluntary, and each participant provided verbal consent prior to starting the interview.

Figure 1 shows Ghana's progress with tackling the issue of AMR within the last decade, from inception to implementation of the NAP. This study was conducted shortly after the endorsement of the Policy on Antimicrobial Use and Resistance with the aim of understanding key stakeholders' perspectives about Ghana's vulnerability to antibiotic resistance, including ongoing efforts to strengthen collaboration for effective implementation of the first strategic objective of the NAP.

The JEE report and AMR policy documents informed the development of the semi-structured interview guide. ${ }^{8,11,12}$ Follow-up questions were also asked to gain insight into participants' experiences. The following research questions guided the study: i) How do stakeholders perceive the challenge of antibiotic resistance in Ghana? ii) How are stakeholders engaged in the implementation of the first strategic objective of the NAP?

The perspectives of various stakeholders were expected to facilitate understanding of the health situation from diverse perspectives. To increase variation, participants were purposely selected based on employment type and workplace location. An initial selection of ten potential key informants from the human health sector were selected from the list of participants included in Ghana's JEE report. Of these, four respondents accepted the invitation to be interviewed. The main reason for inability to give an interview was that some participants were not directly involved with activities pertaining to the first strategic objective of the NAP. Additional key informants were subsequently identified via snowball sampling. ${ }^{30}$ A total of eight stakeholders were interviewed in September and October 2018. Five participants were from the Greater Accra region and three from the Upper West region. Our sample included professionals working in different capacities, including policymakers, health promotion officers, researchers, leaders of pharmaceutical, civil and international organizations (Table 1). Interviews were administered in English. All interviews were completed in-person, with each lasting 30-45 minutes. Interviews were digitally recorded with an audio-recorder, and later uploaded onto a password-protected laptop after 
Table 1. Description of key stakeholders

\begin{tabular}{|l|l|l|}
\hline Health Sector & Key informant (n) & Institutional affiliation \\
\hline Policy & Policymaker (2) & MOH, WHO \\
\hline Research & Researcher (2) & GHS, PS \\
\hline Practice & Health promotion officer (4) & GHS, CSO \\
\hline
\end{tabular}

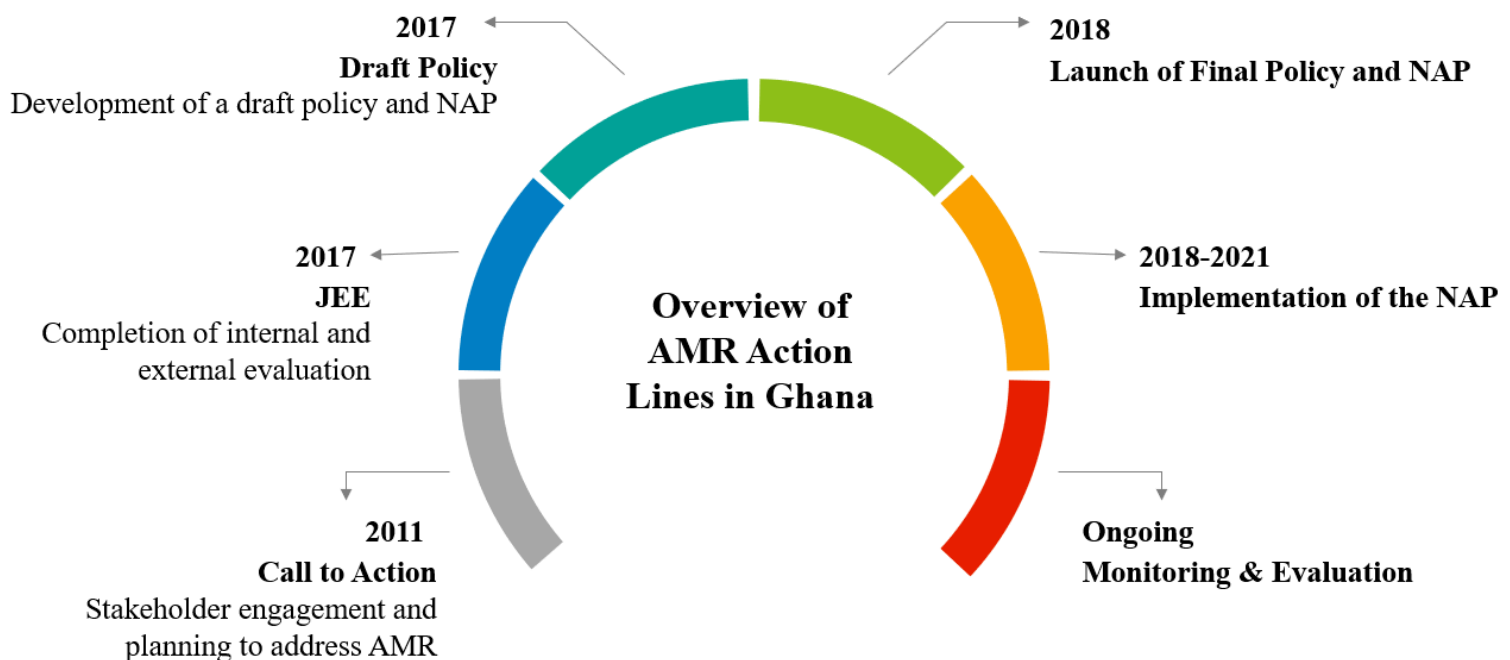

Figure 1. Overview of antimicrobial resistance (AMR) action lines in Ghana

each session.

\section{DATA ANALYSIS}

Responses to interview questions were manually transcribed for data analysis. ${ }^{31}$ Transcripts were read multiple times and initial line-by-line open-coding was conducted manually, tagging key words and phrases in the text that captured the essence of the research questions. ${ }^{31}$ Transcripts were subsequently uploaded into NVivo 12 Pro (QSR International Inc, Burlington MA, USA) qualitative data analysis software and coding was repeated to confirm initial codes, as well as to organize codes systematically for data analysis. ${ }^{32}$ A codebook was created and further expanded as subsequent transcripts were coded. Following preliminary coding, each transcript was analyzed in-depth and constant comparisons were made to synthesize codes into overarching themes, and to attach significance by extrapolating examples from the data. ${ }^{31,33}$ Data analysis was based on the six-phase thematic approach developed by Braun and Clarke. ${ }^{31}$ Data were thoroughly examined, and saturation was reached when no new themes were observed. Coding was conducted separately by two researchers to increase validity of the data. ${ }^{34}$

\section{RESULTS}

Participants comprised four women and four men, with representatives from the Ministry of Health (MOH), World Health Organization (WHO), Ghana Health Service (GHS), Pharmaceutical Society (PS), and civil society organization (CSO). The participants work in one of three health sectors, including policy, research, and practice (Table 1).

The analysis of responses to the research questions showed four main thematic clusters: national burden of disease and antibiotic resistance, policy development, implementation barriers, and implementation strategies. Each main theme also included sub-themes such as vulnerability and causes as presented in the thematic map (Figure 2).

\section{RESEARCH QUESTION 1: HOW DO STAKEHOLDERS} PERCEIVE THE CHALLENGE OF ANTIBIOTIC RESISTANCE IN GHANA?

In assessing stakeholders' perspectives regarding the national burden of disease and impact of antibiotic resistance, two sub-themes, vulnerability and causes, were identified. 

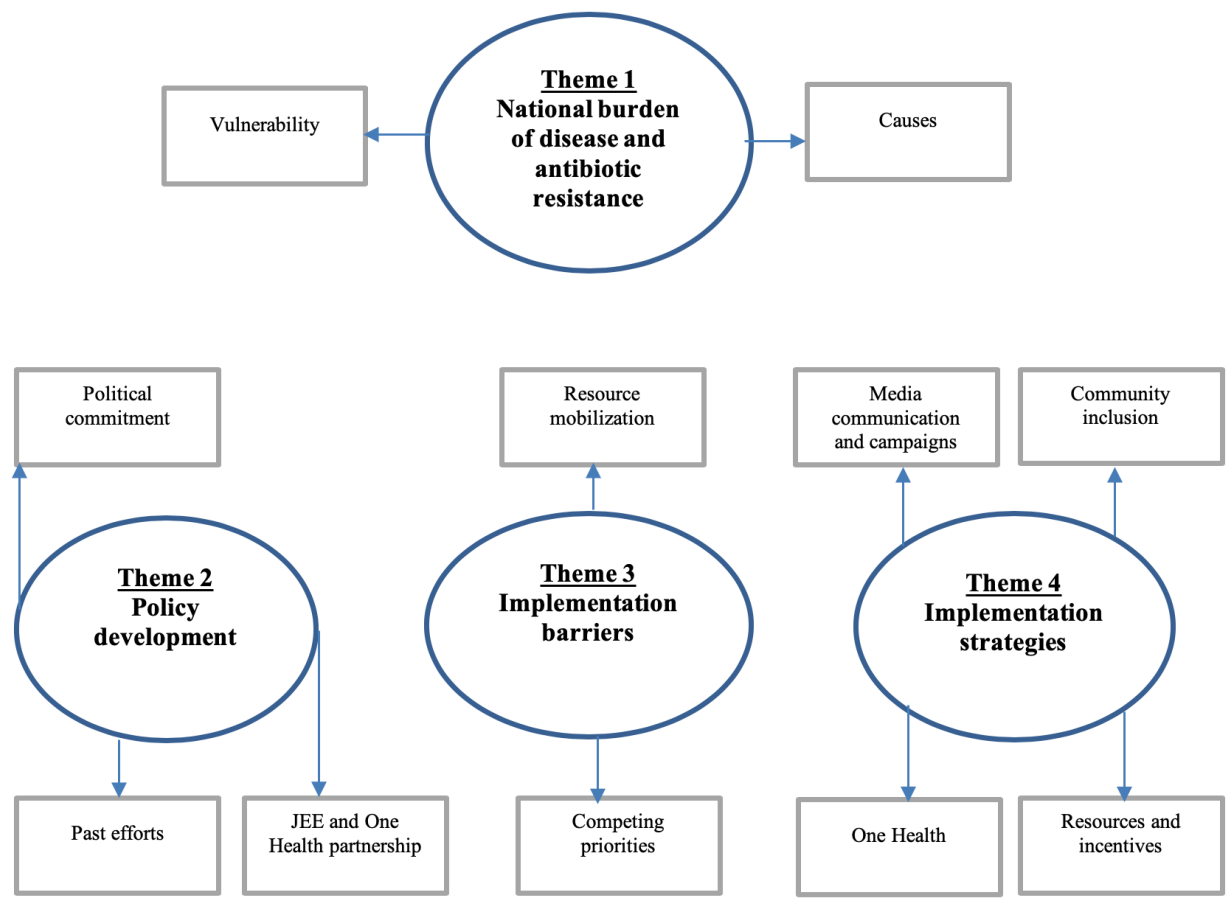

Figure 2. Interview questions and thematic map of qualitative analysis

*Sub-themes are presented in boxes

\section{THEME 1: NATIONAL BURDEN OF DISEASE AND ANTIBIOTIC RESISTANCE}

\section{SUB-THEME: VULNERABILITY}

Malaria, tuberculosis, HIV/AIDS, respiratory and skin infections were listed as major infections contributing most to the country's overall burden of disease. The interview excerpts below present a snapshot of stakeholders' perceptions about the burden of disease in Ghana.

"First one is malaria, upper respiratory tract infections, diarrhea, rheumatism and other joint pains, we have skin diseases. They affect all ages."- Participant 3.

"Malaria, upper respiratory infections, skin infections, diarrhea, particularly in children.”- Participant 4.

"One is malaria; so endemic. You remember that in 2003 there about we changed the policy from chloroquine to ACT. That was the first resistance that Ghana came across...we already have MDR TB in-country, then respiratory tract infections."- Participant 5.

"In Ghana, the first one is malaria. Yes, and I think upper respiratory, at least according to the national health policy, upper respiratory tract infections. Now it is $T B$. TB outside the HIV community is not very high but TB inside the HIV/AIDS community is high, that is where the problem is, and of course when the direct observation treatment (DOT) is not working or people are lost to follow-up then they get some of these superbugs."- Participant 6.

Several participants also noted the rise in non-communicable diseases (NCDs) as a growing concern, specifically, stroke, diabetes, and hypertension.
"NCDs are on the rise. Now we're middle-income and so we're eating all those junk foods, fried foods. We have KFC, Burger King, all those processed foods. We didn't use to eat all that."- Participant 2.

"...then hypertension and those non-communicable diseases in the elderly."- Participant 4.

"Of course, there is also the NCDs- hypertension, diabetes."- Participant 6.

"Now, we have non-communicable diseases coming up; diabetes, stroke, hypertension.”- Participant 7.

Furthermore, all eight stakeholders expressed concern about the threat of antibiotic resistance and vulnerability of communities. The following quotes shed light on participants' views.

"Yes, we have MDR-TB. Some time ago the Children's ward at Korle-bu was shut down because of MDR-TB and so we need to really do a lot in that area."- Participant 2.

"I think that even in Ghana, was it 3 years ago when we were doing as part of an outreach in the Eastern region and somebody came and brought us his lab report with culture and sensitivity which showed the sample that had been taken. So many were not susceptible and so he couldn't be treated...I think it was the UTI ...we are vulnerable, and I think in Ghana it is something that we take very very seriously, and it is something that we really want to do our part."- Participant 6.

\section{SUB-THEME : CAUSES}

Also highlighted was the multifactorial nature of antibiotic 
resistance. The following causes were attributed to the imminent rise in bacteria resistance in communities.

WEAK ENFORCEMENT

"The thing is that the pharmacists have registered the premises but they're not there and we have very low caliber people working there who do not understand the issues around the medicine. The other thing is also lack of enforcement of policies in the country. The cause is that we have the laws and we can't enforce them. You're supposed to buy antibiotics with a prescription, but people will go the chemical shop or pharmacy to buy. The law is there but enforcement of the law is the problem. We have said that some of the issues will be legalized but we have a lot of legal issues which we can't enforce."- Participant 2.

"The policy on antibiotics is not strictly adhered to. It is an "A" drug which must be only prescribed by a medical officer, but you see that most of them they just go to the chemical shop and sell them...antibiotic sale is not controlled."- Participant 3.

"I think it's the regulatory framework that we have to look at because it is amazing how all of these antibiotics enter the market...the policies are already there. The issue is about enforcement."- Participant 4.

"The weak regulation, the irrational use by providers, community, policy makers, then the area of environment, the industries, who knows how they dispose of beta lactam products, where does the waste go? Of course, we know that spurious medicines are circulating in our markets. So, it's a multiplicity of issues."Participant 5.

"It is the control...you see people selling antibiotics over the counter...you can buy, you can sell. People look at the money more than what is right. It's the regulatory side."- Participant 8.

Moreover, informal sale and smuggling of substandard medicines were cited as consequences of weak enforcement, as shown below.

"We have over the counter drugs and now we have a lot of chemical sellers who are not licensed to sell antimicrobials, but they do. Because you can go any drug store and buy those antibiotics without prescription...the chemical sellers sell in bits and pieces to people."- Participant 1.

"You know, access to medicines in rural areas is not that good and we have a lot of rural areas. On market days you see people with antibiotics on the floor, people selling "tupaye" in their bags, selling them one by one.”- Participant 2.

“...when you go to the borders, they normally pass through there instead of passing through the FDA. Another thing too is the fake; maybe the concentration of the active ingredient, they can write Amoxicillin $500 \mathrm{mg}$, but when you go and do the test you realize that it's less, about 200mg...therefore helps the organism become resistant."- Participant 3.

"You can still see in the market people have exposed medicines and people are buying. It's not on prescrip- tion, and these are antibiotics- they're not just pain killers. When I do some visits to markets, I do that sometimes- observational research, you'll find that people have spread mats, and the medicine is there and they're selling. So, community use of antibiotics actually is not use- it's misuse"- Participant 4.

LACK OF KNOWLEDGE AND AWARENESS

There was also consensus among participants about the inappropriate use of antibiotics in communities caused by illiteracy and unawareness.

"I don't abuse antibiotics because I know the implications. If everybody were to know, it will reduce the problem to a large extent, but people are doing it out of ignorance, and people think if you have a cold you take let's say, Septrin, which is a very basic one, 2-3 days you get some relief and you throw the rest away. If people knew what that meant, probably they will not do it. Half of the people are doing it because of lack of knowledge."- Participant 1.

“They think when they get to the hospital, they'll be made to pay money. Probably the greatest issue is lack of information. They're uneducated about the risks. They think it will be an extra cost to access formal facilities."- Participant 3.

“Oh, I think it's ignorance. It's lack of information because right now access to health services is not the issue. Within every $5 \mathrm{~km}$ we have a health facility, so the issue is not access to orthodox medicine. The issue is information and perhaps poverty. Ghana is extremely vulnerable because we still have a largely illiterate population, and to the extent that we still have people not going for prescription drugs obviously tells you that we're vulnerable."- Participant 4.

“Well, most of us don't take all our medications, that's one. We don't understand, I mean it is with the study of microbiology that perhaps we understand that the fact that you are feeling better does not mean the condition is resolved, and the general public does not know that. For instance, the most common drug, pain relievers, we tell them that when you feel better stop. So, it is easy for them to transfer that to whatever they are taking."Participant 6.

"You know in Ghana we have very high literates and illiterates. A lot of people don't know. One reason why we stepped in is we knew that most of those happening in the hospitals, the bigger one is in the community, because they don't know. We should start looking at how we can communicate it to the lowest person who has never been to school to understand. So, we use more pictorial, we use things that they can understand because they are part of the problem. Empower them also so that when they get to the facilities they are empowered to demand and ask questions."- Participant 8.

PRESCRIBERS’ AND DISPENSERS' ROLE

In addition to the role of individuals and communities, prescribers and dispensers were identified as important drivers in the fight against antibiotic resistance.

| “Also, we need responsible use. People prescribe an- 
tibiotics anyhow, especially now that the national health insurance will pay, people prescribe loads of antibiotics."- Participant 2.

"I think there's a lot more to be done. We need to engage industry more because you cannot have a good stewardship program without points of care and diagnostics, and so if you want to get the doctors to prescribe well, then give them an opportunity to test their patients, just like how we do with malaria. There's a point of care diagnostics that you test to see whether the person has malaria or not, before medicating. When we do that for antibiotics, we will be able to reduce the irrational use."- Participant 5.

"...then, of course, there are also times when prescribers are not prescribing according to guidelines. So, instead of taking the first line of treatment, you think that the person can afford a stronger medication and you feel that you don't want to inconvenience the person because the person may go and not feel well and has to come back and do the test, so they just go to the second line or third generation antibiotic.

Also, you are supposed to get antibiotics from a pharmacy only, and it is supposed to be under the supervision of a pharmacist. But the reality is that there are times when the pharmacists are not in the facilities. So, if the pharmacist is not in the facility and there is no requirement for the other personnel to contact the pharmacist before dispensing, then they'll go ahead and dispense."- Participant 6.

\section{RESEARCH QUESTION 2: HOW ARE STAKEHOLDERS ENGAGED IN THE IMPLEMENTATION OF THE FIRST STRATEGIC OBJECTIVE OF THE NAP?}

Further analysis identified three main themes that addressed the second research question (Figure 2): policy development, barriers, and strategies to effective implementation of the NAP.

\section{THEME 2: POLICY DEVELOPMENT}

Participants discussed prior steps the country took to address antibiotic resistance, including respective contributions made to the development of the Policy on Antimicrobial Use and Resistance, as well as merits of completing the JEE.

\section{SUB-THEME: PRIOR EFFORTS}

The following quotes summarize the opinions shared by respondents regarding the country's past efforts to control antibiotic resistance.

"The earlier work by WHO on combatting drug resistance was the initial thing that even brought us together to start thinking of AMR, so when this one (JEE) came there was already a lot of concept. So, I got to know and read a lot about drug resistance during the time when the WHO made it an issue of public health concern. So, we have been on antimicrobial resistance even before the JEE came. Five-six years ago, the theme for World Health Day was on antimicrobial resistance. We organized radio and television programs and got re- source persons to talk to the general public. We did feature articles in the newspapers."- Participant 1.

“That's what we've been doing. We have surveillance units in all the districts. We have Disease Control Officers in all the districts, and we have Health Promotion Officers. So, these are the people who do that in the communities. We do monitoring, and then the regional level discussions. You see we will continue to increase awareness. What we're doing now is lobbying with the radio stations to give us airtime."- Participant 4.

A representative also noted their organization's ongoing role in educating local communities about the rational use of medicines, which subsequently gave them a place at the table during the policy development.
"What we are also doing is getting people on the ground to organize groups for us and we go and talk to them about rational use of medicines...we do adherence counseling; we set up clinics in public places and phar- macists come there and volunteer their time and talk to patients. So, it is something of great concern to us. They have been ongoing even before the launch of the $J E E$, and it is also because of that that we were invited to the platform."- Participant 6.

\section{SUB-THEME: JEE AND THE ONE HEALTH PARTNERSHIP}

During the interviews, it was evident that although there were ongoing efforts to mitigate the problem of antibiotic resistance, the scores reflected by Ghana's JEE assessment in 2017 were not encouraging. There was shared disappointment about the low scores.
"One of the security agenda of the JEE is about AMR and we had already done so much; we had developed the policy; we were doing the national action plan even before the JEE came. So, our work just fitted into the JEE process. It was a draft policy; it had not been launched, so we scored low even though we had the draft document. It hadn't been launched and a few components like the infection control had not been in- stitutionalized. It was like half and half, so we didn't score much, but there was work in progress, so we were very sad."- Participant 2.

"The JEE, the first time it came it was a very painful path for us because we worked so hard as a people and we came out with our situational analysis, we came out with our policy, and we also came out with a national action plan. The JEE was done in 2016, and we sent it to the Cabinet for approval, unfortunately, there was a change in government and so that 2016 was 0. So, when the JEE came for evaluation, we scored virtually 0 everywhere, because we did not have an approved plan."- Participant 5.

Nonetheless, although JEE results may not have been a complete reflection of Ghana's performance, participants noted the benefits of undertaking the evaluation exercise, particularly in complementing prior country activities and promoting cross-sectoral collaborations.

\footnotetext{
"It puts everything in perspective. We have 19 different areas, and as a country we need to know where we are by way of preparedness. So, it was like prompting from
} 
outside that as a country we need to put our house in order. We were part of the team of people from environment, agriculture, fisheries, civil society, so we all sat down and looked at the objectives one after the other and each one what you can contribute to make it work."- Participant 1.

"You know, we started the AMR in the One Health approach, so it was a platform to continue with the other aspects of the JEE. It was just a smooth transition to the bigger JEE. What we told the JEE was that we already had that system, not that it wasn't new, but we were happy because it was time to bring everybody together because health is so involved and everybody is doing their own thing so it was good to bring them all together to coordinate. The JEE is well-structured so you know what the item is, line-by-line things you're supposed to do. That helped us to also file our reports and how it should look like, so it helped. So, we thought it was a good thing."- Participant 2.

"We had a platform of everybody. We had media, civil society organizations, we had the veterinary people, food, environment, etc. I think we had 2 or 3 consultants who were moving it. We had so many meetings. We used to meet regularly...and because we had the policy it was easy to do the national action plan based on the policy, and the policy is also based on the Global Action Plan, so it was easy to transfer."- Participant 2.

"You will recall that AMR piece of work has 4 Ministries involved. We have the Ministry of Environment, Science, Technology and Innovation, Ministry of Food and Agriculture, Ministry of Fisheries. We work with the Veterinary group within the MOFA. If you take civil societies, for instance, Hope for Future Generations, they have been going to the communities to educate them. They have the Queen mothers Association whom they're using. They have done a lot of work on AMR in the Central Region. They are all part of the platform. The Lady Pharmacists Association is another. We have a platform that all these people come together to come out with this document. There is a whole program on awareness in the Action Plan. You know behavior change takes a long time and so we will be taking baby steps, but the baby steps will lead to giant steps so, I think that we are making progress. The first step is to define where we want to go and that is what we did in this document."- Participant 5.

Similarly, ongoing external collaborations with international organizations including ReAct, the Fleming Fund, and the WHO were evident and instrumental in supporting country efforts.

"ReAct also helped us develop the policy. The technical working group, we used to call it ReAct Ghana. So, people travelled to other countries wherever they have AMR to learn and contribute, e.g. India. ReAct supported. Some people went to other countries like South America to learn about how they're communicating with the schools, with the general public, to see how their AMR awareness creation was done. I remember we went to Malaysia and Sweden.”- Participant 2.

"The Fleming fund has now come in-country. They have selected the university as their host agent so about 5-7 laboratories have been selected for action.
The WHO has come out with the AWARE program where those antibiotics that must be used when critical, moderate, etc. We have also incorporated it into our Essential Medicines List so if we can all enforce that one also, I believe we will get somewhere."- Participant 5 .

\section{SUB-THEME: POLITICAL COMMITMENT}

Generally, there appeared to be a positive outlook on implementing the NAP, with support from the Government of Ghana to advance the policy agenda.
"I learned when they were doing the launching the president was there; Nana Akuffo Addo was there so that political commitment and support should be there. We did a national launch that brought in the Minister and all relevant secondary and tertiary target audience to do advocacy on the topic of AMR."- Participant 1.
"I am very happy that the president launched the NAP
and his eye is on it"- Participant 2.
"The President in his speech requested that the in- dicators for the AMR policy be incorporated into the SDG monitoring mechanism and requested the Attor- ney General to move some of the issues into legislation. This particular document (NAP) has come with moni- toring and evaluation and timelines and the $\mathrm{MOH}$ has put it onto their aid memoire. Every year the ministry signs agreements with the partners and the areas by which they should measure them. So, for 2018 one of the deliverables is to provide an update on the imple- mentation of AMR. As part of that the ministry is also co-hosting the Call to Action in Accra, so all these are adding up to what we want to do and to ensure that ac- tion plans are implemented."- Participant 5.

\section{THEME 3: IMPLEMENTATION BARRIERS}

As with any new policy, several roadblocks may be encountered during the implementation phase of action plans. Stakeholders shared some challenges faced with executing planned activities.

\section{SUB-THEME: COMPETING PRIORITIES}

The following quotes describe potential setbacks to implementation of the NAP due to differences in priorities among the four ministerial sectors.
"Now I think that too many people are also doing verti- cal things...everybody wants to do something."- Partic- ipant 2.
“We've been having a difficult challenge trying to foster the collaboration because the budget for vaccinating the animals doesn't come to us."- Participant 3.
"Ok, at this time I think that at the top that national collaboration is very effective, but coming down to the ground, it's not as effective."- Participant 6.

\section{SUB-THEME : RESOURCE MOBILIZATION}

From the discussions, the major challenge preventing organizations from efficiently executing planned activities was unavailability of adequate financial resources. 
"When they have an allocation for AMR and they channel it through the pharmacies, they don't include the awareness creation component. They're looking at the technical people, not the communication people, so it's sort of we're left behind. When they're doing the proposal, there's a component on health communication, and when it comes it's ran there- the monies are not brought to us, so we have no funds to do some of the things."- Participant 1.

"First, it's funding; that is the major thing. A lot of the things, even though they're ongoing, like in the lab, they will need antibiotic discs to do certain tests, they don't have it. Also, even though we have the media, it should be frequent, always engaging the people. Sometimes when you go to maybe $G B C$ is free, but stations you have to pay to get airtime, so it always comes back to funds. We got some airtime with GBC, I think for the whole month, and it was nice."- Participant 2.

"The issue is the National Health Insurance Scheme (NHIS) cannot pay the bills. Although some of the medications are covered by NHIS, we have dispensed them and 7-9 months, they're not paying our facilities. How do we stock them?'- Participant 3.

"The first one is finances because we have to do the airtime and we also have to travel to do the surveillance and the monitoring and supervision. And we have to travel to insist that people should not sell antibiotics in the open under the sun. Increasingly, our resources are getting limited. We need transport...because we need to do enforcement of antibiotic laws- we need to move (transportation)"- Participant 4.

"Funding is one. Then we talk of means of transport. We have a lot to do; we need to go to the community. You need fuel and a vehicle to go out to the community. The thing is we need some equipment because we need to shoot a video or design a poster, and mount it where the people can see...as I said the radio is the major this thing, but we need to also get to the ground to meet the people there to have interaction."- Participant 7.

\section{THEME 4: IMPLEMENTATION STRATEGIES}

In discussing the possible strategies for effective implementation of action plans, participants shared various experiences required for positive outcomes, including strengthening cross-sectoral collaboration, community participation, adequate resources, and effective public communication.

\section{SUB-THEME: ONE HEALTH}

Many highlighted the crucial role of the One Health partnership and the need to enhance collaboration with the animal, environment, and human sectors. A recommendation that was brought up by most participants was the need to view the problem of antibiotic resistance as a shared responsibility.

“Bring other stakeholders on board-immigration, GHS, environmental people, also mobilizing the chiefs and people so that they can report the fake drugs. Also, we know if birds are dying or if birds are sick, we can cull them. I always ask, if human beings are sick can we kill them? No. So it is important. We're always worried be- cause we know that if they fail, the bigger problem will come to health. So, we're always interested in solving the problem at the animal level so that it doesn't come to humans."- Participant 1.

"We need champions everywhere...we need champions to bring the issues out and discuss them and try to find solutions. We need people who are always on it, because the national policy is good, the NAP is good, but we need people to implement."- Participant 2.

"We have learnt one lesson working with the Tripartite, that nobody should apportion blame. All of us are responsible and all of us must find solutions to it, including industry and regulators. I think that we see ourselves as equal partners and our luck is that we have 4 pieces of UN bodies supporting our work; FAO, WHO, OIE, have been supportive, and recently UNEP has been supportive, and the Environmental Minister, Prof. Frimpong- Boateng, and the other sector Ministers have been supportive. So, I think that we are all equal partners. We have identified them in the action plan and each of the sectors has to come out with a plan on addressing the issue."- Participant 5.

"Perhaps one of the ways is to maybe encourage pharmacists to go into animal health, because pharmacists are more focused on human health. So, it is veterinary officers who also provide the pharmaceutical services for the animals. So, it is distinct, but if there were pharmacists in animal health, what that would do is to bring that part to the focus...and will allow pharmacists to perhaps envision more than human health."- Participant 6.

"Maybe we should have meetings often so that we see each other as partners. Those outside the health sector should be included in some of our programs, because if we allow them to be doing their own thing then we'll all be working in silos. So, there should be more meetings, more interactions and be able to see all of us as working towards a common goal."- Participant 7.

"Partnership is very important...we should look at the capacity of everybody and what people can do, their various roles and get them on board. It shouldn't just be only health. I'm a health person but I realized that health alone won't, that is why I go to the community. I see that there's a lot more to do than just sitting at the facilities and offices. That is what everybody needs to appreciate, if they don't do that so much money will be going, and nothing will change."- Participant 8.

\section{SUB-THEME: COMMUNITY INCLUSION}

Another salient point raised was the invaluable role of community members since the effectiveness or uptake of any new intervention largely depends on community reception.

"I think for communities the moment you build their capacity and you recognize them, they accept, and there's sustainability. We see them as a major player in our work. We don't just impose it on them. They are a unique group of people, and if you don't get them involved or appreciate their contribution, you'll come in and fail. If we only focus on national level, we will fail and that is where we have a problem. So, most of the community members are frontline staff for us. We train 
them and use them. That is what we're trying to promote government to do...we should work in collaboration because we are now middle income and donors are not bringing the money and even if they bring, they'll want results, so we must work together."- Participant 8.

"First of all, let's consider the people at the community level when we're designing messages. Let's get them right from the planning so that sustainability will be strengthened. We're now moving away from the element of the individual; we're now using the community. Secondly, we are at a point when the community wants to be involved in all processes, so the chiefs and others have to be involved in the process so that by and large they are aware that this is happening in the community."- Participant 7.

One stakeholder also described how the involvement of communities in health interventions could empower people to take initiative to improve conditions.

\begin{abstract}
"We should use the bottom-up approach instead of the top-down. We're seeing certain improvements in our health facilities; immunization and other efforts. Now even some communities have put together their resources and they're building a delivery room on their own. They have even roofed it, without government intervention. We also try as much as possible to use various communication strategies we call SCBC, Social Community-based Change, to reach out to the people...we believe when people are empowered or are given that information and they have health literacy, it ultimately results in them taking control of their lives."Participant 7.
\end{abstract}

\section{SUB-THEME: RESOURCES AND INCENTIVES}

Adequate resources, both financial and human, were also identified as vital to ensuring smooth implementation of action plans. Many emphasized the challenges of developing educational materials for the public, as well as getting airtime to disseminate health messages via the radio due to inadequate financial resources.

"It's support. We need support- funds. As for what to do, we know exactly what to do, and we can put that on paper. The resources could be financial and others. As we sit, we have our staff at regional and district levels, and we want to produce standard information. For instance, we can produce posters, leaflets that will have the standard information, print and distribute to everybody in the country. We can conduct radio and tv programs. If we get the needed technical information to our district technical district officers, every district now has some FM station- they can go to the FM station and talk to people. If you get the needed information across the country, we can use that to talk to people in churches and mosques in communities and everything. So, we can touch as many people as possible if the resources were available."- Participant 1.

" 'You know, when you're communicating you need a lot of money. It's not cheap to use the radio, to develop Information, Education and Communication materials."Participant 5.

Some participants also emphasized the impact of incen- tives in raising awareness about antibiotic resistance, while others made a few recommendations on how incentives offered to pharmacists could improve antibiotic use and dispensing in local communities. Suggestions included tax incentives for personnel working in rural settings, or awards for pharmacists who routinely record interactions with patients and report adverse drug reactions of dispensed antibiotics.

\begin{abstract}
"As part of our set of activities we sort of motivated people, that if you write an article that has AMR within this period, we'll give you something (monetary award). So, people did a lot. It's always our target that when we launch an activity, we sustain the information over a period."- Participant 1 .

"Right now, about $90 \%$ of the community pharmacies are based in the Greater Accra and Ashanti regions, but there are 10 regions in Ghana. It is not economically attractive for a pharmacist to go to a rural area, and there is no policy in place to support such a person. Access to proper pharmaceutical service which means access to proper counselling when you are taking the medication...if the government policy also supported people who wanted to go into the community, and maybe said for 5 years no tax so we give you tax incentive and for the next 5 years it would be half of what you normally pay, then it is an incentive."- Participant 6.
\end{abstract}

\begin{abstract}
"If we're talking about enforcing the regulation on prescribing, I know that the FDA, for instance, has an award for pharmacies and pharmacists that report adverse drug reactions (ADRs). So, what that does is the pharmacists will encourage their patients to come back if they have problems, so that practice is something that we can learn from. For instance, if we want to look at if people are complying with dispensing, we can get them to record the times that they spend with patients, if it is possible to trust them. We get them to report the times and the things that they discuss, or even like a manual which they have to tick... what that does is to keep the people on their toes to make sure that the checklist is followed. I don't know if it is done anywhere but I think that it's something that could be done. I think the other way is, for instance, perhaps, the people in veterinary practice can get pharmacists in their communities more involved in their work. Or perhaps, pharmacists should also look for opportunities to be involved in the work of veterinary practitioners."- Participant 6.
\end{abstract}

\section{SUB-THEME: MEDIA COMMUNICATION AND CAMPAIGNS}

Social media platforms, including Facebook and WhatsApp, were identified as novel methods to transmit health information, not only to communities, but also between colleagues in the health sector.

"We're not training people to become pharmacists, but
we want people to have the correct information, so it's
multiple channels we're going to use, including social
media which is becoming big these days. If you put cer-
tain information on Facebook, WhatsApp...there's a lot
that can be done to change the situation."- Participant
1 .

| "...and we also have the WhatsApp group, so, we at the 
region we have our platform and those at the districts also have their own platform."- Participant 7.

All participants identified media outlets as effective channels of reaching a broader audience. Particularly, radio stations were identified as key modes of communication given the flexibility of reaching diverse ethnic groups in the different local languages. Below are a few excerpts on the role of the media in promoting public awareness.

\begin{abstract}
"Radio has the flexibility of local languages. Sometimes when it comes to organizing $t v$ and radio shows our officer here will organize them, get slots, get resource persons. That's the role we play now. We can conduct radio and tv programs...every district now has some $F M$ station- they can go into the FM stations and talk to people."- Participant 1.
\end{abstract}

"By mass media- radio first...in Ghana almost every language you can get a radio station. So, if you get a predominant language it would be effective...it depends on the information you want to send out. If it is to get interest for them (communities) to get talking and want to get more information about it, then mass media, but if it is to ensure that the practice is effected now, then one-on-one or focus group discussions, or a social gathering."- Participant 6.

"We have about 8 radio stations in town and all of them have given us 1 hour each, so weekly, we have various health themes and topics. Some of them depend on the spur of the moment...we also review our records...when we have management meetings and know what diseases are upcoming, we educate the people."- Participant 7.

In addition to the different media outlets, the recent World Antibiotic Awareness Week (WAAW) campaigns have been instrumental in raising public awareness about antibiotic resistance and the need for prudent use of antibiotics. Participants described various activities their organizations were involved in during the WAAW campaign, including plans for future campaigns.

"Normally, when you go to the hospitals, they have some communications, posters, sometimes they have oral talks. Normally we have the open discussion where people (both patients and non-patients) come to the hospitals for general talks."- Participant 3.

"Last year, for instance, Hope for Future Generations and some professional associations took it upon themselves to speak on radio and use social media. In two weeks, there will be Antibiotic Week and I know the professional groups, especially the pharmacy and nurses, they go to speak to the young people. They go on radio and speak in all the dialects from the Northern region up to Greater Accra. We have a lot of plans. There's a committee that is working on that. It's normally the whole week. They'll do the launch, the media will be there, they'll do symposia, go to the community, provide talks in schools. It will be cross-sectoral. We'll have the animal side, food side, fisheries, and environment. These programs are in all the regions."- Participant 5.

| "What we will do is we will issue a statement on that; why it is important. We're also trying to engage in various mass media to go on the radio and talk to them about. Also, we have a branch in every region so we get them to go to the regional radios to talk about what is happening, and so it is mainly awareness creation and improvement and education about what they can do. We also get the community pharmacists to use that time to talk more about AMR."- Participant 6.

"For us we'll be celebrating in one of the districts. We don't get money for it, so we go the communities with our posters, meet queen mothers, talk and we're done."- Participant 8.

\section{DISCUSSION}

The analysis of stakeholder perspectives on the implementation of action plans to address antibiotic resistance revealed convergence of cross-sectoral concerns about the significance of the problem in the broader context of population burden of disease. Also revealed were potential barriers to implement policies designed to reduce the impacts of risk factors implicated in the emergence and proliferation of bacterial pathogens that are increasingly resistant to antibiotic therapy. This analysis describes key stakeholders' perspectives on Ghana's population vulnerability to the impacts of antibiotic resistant infections, including ongoing efforts to strengthen collaboration for effective implementation of the first strategic objective of the NAP. ${ }^{11,12}$ We sought to better understand this process by examining two broad research questions of interest. The first research question provided context on stakeholders' perceptions of the country's overall burden of disease and the threat of antibiotic resistance. Identifying existing health gaps serves as an initial step towards understanding current needs and priorities, which subsequently allows for targeted interventions.

\section{NATIONAL BURDEN OF DISEASE AND ANTIBIOTIC RESISTANCE}

The list of infectious diseases prominent in the national burden of disease were identified by stakeholders, and represented a reflection of previous studies. ${ }^{22,35}$ Participants attributed a major portion of the country's total disease burden to malaria, HIV/AIDS, tuberculosis, respiratory infections, as well as non-communicable diseases such as stroke and diabetes, many of which rank among the top causes of death, years of life lost due to premature mortality, and DALYs in Ghana. ${ }^{22}$

Similarly, antibiotic-resistant infections, particularly the multidrug-resistant, were cited as a major concern. This is also evident from other national and global studies that have reported high prevalence of multidrug-resistant bacteria in hospitals and communities. ${ }^{1,2,36-38}$ Several causes of antibiotic resistance and misuse of antimicrobials in communities were identified and were mainly attributed to weak regulations, illiteracy and the lack of awareness in communities. About $40 \%$ and $25 \%$ of women and men, respectively, have only a primary level education or lower in Ghana. ${ }^{39}$ This is important to note given that educational attainment may be associated with health literacy, and could impact community knowledge about resistance, and 
subsequently the use of antibiotics. ${ }^{26,27,40}$ Likewise, low levels of education may limit public information campaigns on antibiotic resistance and therefore calls for further research to reveal other supplementary ways to communicate information to the general public. For instance, examining differences in human development index values across countries may shed more light on effective approaches to implementing public health programs.

There was also a consensus among stakeholders that while there exist national regulations prohibiting the sale of antibiotics without a medical prescription, these regulations are rarely adhered to. Although Ghana has guidelines to control the sale and purchase of antimicrobials, enforcement has been problematic due to several factors including funding for monitoring and surveillance. ${ }^{41}$ This is especially relevant since the informal sale of antibiotics, particularly those of substandard quality, will require effective and sustained regulation. The recent development of the Policy on Antimicrobial Use and Resistance, together with action plans outlining respective responsibilities of various sectors, presents an opportunity to curb this global health threat. ${ }^{11,12}$ This comprehensive policy aligns with objectives of the Global Action Plan, ${ }^{3}$ and discussions with stakeholders suggested strong national commitment to prioritize antibiotic-related programs.

Likewise, the role of prescribers and dispensers remains paramount given that medical prescriptions have been found to influence self-medication practices. ${ }^{23,42}$ Some participants from our interviews reiterated the need for health professionals to follow appropriate guidelines by obtaining a confirmatory diagnosis prior to prescribing antibiotics. However, it is important to note that ensuring physician adherence to the proper protocol will require accessibility to the necessary diagnostic tools. There was also concern regarding the sale of antibiotics by unlicensed dispensers. By law, no individual may dispense medicines unless they hold qualifications outlined in the Health Professions Regulatory Bodies Act, 2013, Act 857. ${ }^{9}$ These issues are interrelated and speak further to the aforementioned point pertaining to the need for enforcement of regulations.

\section{POLICY DEVELOPMENT}

The second research question focused on the policy development process with the goal of identifying potential obstacles and solutions to effective implementation of the first strategic objective of the NAP. Before the inception of the Policy on Antimicrobial Use and Resistance, there were several ongoing activities aimed at raising public awareness on the rational use of medicines. For instance, one stakeholder recalled leading organizational efforts to inaugurate the World Health Day on Antimicrobial Resistance. ${ }^{43}$ Civil society organizations such as Hope for Future Generation and the Lady Pharmacists Association have been actively involved in organizing community outreaches to educate and raise awareness on public health, including AMR-related topics. Participants also described how the introduction of the JEE provided a roadmap and was instrumental to promoting cross-sectoral partnerships, while complementing past and ongoing public health efforts. The JEE is embedded in the International Health Regulations and involves a voluntary and transparent assessment conducted to determine country capacity and existing gaps for enhanced decision-making to strengthen global health systems. ${ }^{6,7}$ A previous study assessed the JEE process in the WHO Africa Region and reported several lessons learned from the evaluation procedures across the continent, some of which were reflected in the responses from participants in the current study. ${ }^{10}$ For example, the study identified setbacks in some countries' commitments to conduct the JEE due to competing national priorities. ${ }^{10}$ As highlighted by the stakeholders involved in Ghana's assessment, one of the requirements of the JEE is to have an approved action plan. Although Ghana had a draft plan, it had yet to be officially launched. Recent political factors such as the change in government slowed the pace of activities, thus preventing the country from having an approved national plan at the time of the JEE evaluation. This consequently resulted in low scores reflected in many of the indicators. ${ }^{8}$

Despite disappointment in performance scores resulting from the JEE, stakeholders commended the process, stating that it was well-structured, complemented prior efforts, and provided a conducive environment for discussions among diverse sectors who may otherwise not have had a common platform to coordinate activities to address AMR. For example, in addition to the four main ministries involved (Ministry of Environment, Science, Technology and Innovation, Ministry of Food and Agriculture, Ministry of Fisheries and Aquaculture Development, Ministry of Health), civil society organizations were also closely involved and shared experiences of engaging with local communities given their vital role as recipients of the policy agenda. In addition, the government's engagement and political will to address antibiotic resistance were evident given that Ghana launched the Policy on Antimicrobial Use and Resistance, together with the National Action Plan, not long after the completion of the JEE. ${ }^{11,12}$

Findings from our study corroborate existing literature on the importance of the One Health approach in framing the antibiotic resistance challenge. ${ }^{13,14,44,45}$ The interconnectedness of people, animal, and plants requires multisectoral solutions to global health problems. Effective implementation of activities to mitigate the threat of antibiotic resistance will therefore require an interdisciplinary effort. Adopting the One Health approach has the potential to improve disease surveillance and reduce infection transmission through early detection and control. As described by participants, cross-sectoral partnerships are invaluable to the fight against antibiotic resistance. Participants also described several instances whereby collaborations, particularly between the human and animal sectors, were instrumental in controlling the rapid spread of infection. For example, veterinarians can help us better understand communities' relationship with animals, as well as proper animal husbandry behaviors for both subsistence and commercial farmers, such as safe handling of sick animals to prevent the spread of zoonotic diseases. However, the absence of national guidelines for antibiotic use in animals in Ghana makes it difficult to monitor activities. ${ }^{41}$ The recommendation by one of the participants regarding the need to provide pharmacists with training on animal health has been shared by other researchers. ${ }^{46}$ Previous studies have 
also reported several benefits of advancing the One Health approach through multi-sectoral collaboration, including early detection and prevention of infections at the source. ${ }^{13,14,44,45}$ Hence, stakeholders' shared views about strengthening the tripartite partnership among the human, animal, and environment sectors, is in the right direction.

\section{IMPLEMENTATION BARRIERS AND STRATEGIES}

This research revealed gaps and potential challenges that may affect implementation of the national action plan. For instance, several participants referred to competing priorities within the tripartite body, describing how these distinct sectors have varying agendas and different priorities for chronically insufficient operating funds, which could impact implementation. This is to be expected since these sectors have different mandates and have been traditionally hosted in different ministries. To mitigate this problem, participants suggested that sectors view the problem of antibiotic resistance as a shared responsibility and act as equal partners working actively towards a common purpose.

Resource mobilization, specifically inadequate funds, was repeatedly identified as a setback to implementation. For instance, some participants shared their department's inability to successfully execute plans due to lack of funds. Radio and television, for example, comprise effective modes of communication to reach majority of the population given their flexibility to broadcast in multiple local languages. ${ }^{47}$ However, inadequate funding limits the amount of airtime available. More recently, social media platforms, specifically, Facebook and WhatsApp, have been identified as important channels for exchanging health information. ${ }^{48}$

Another crucial element is the inability of laboratories to purchase appropriate resources to enable health professionals to conduct the necessary diagnostic tests to inform therapy, including antibiotic prescriptions. Inadequate infrastructure in the form of reliable transportation also prevents community health workers from attending to the needs of communities, particularly those remotely located. Discussions with stakeholders further revealed that local community leaders are expected to play an important role in the design, implementation, and sustainability of health interventions. ${ }^{28,29}$ It is therefore important to invest in adequate resources to allow health workers to travel to underserved communities to raise awareness about antibiotic resistance and educate individuals on the prudent use of medicines. A suggestion made by one of the stakeholders was to provide tax incentives to health workers willing to practice in remote rural settings. Successful implementation of the NAP will therefore require efficient resource mobilization to enable the respective sectors to carry out needed activities.

\section{STRENGTHS AND LIMITATIONS}

This study adds to the knowledge base by advancing Ghana's efforts to address AMR, as illustrated in Figure 1. Key stakeholders were purposely selected from sectors related to health policy, practice, research, and civil society organization, given their instrumental roles in ensuring effective implementation of the first strategic objective of the
NAP. The interviews revealed several important factors, including potential challenges and strategies to realizing the national action plans. Moreover, stakeholders were representatives of both the urban and rural regions, thereby providing a clear perspective of these distinct settings to inform the development of targeted health interventions. Another strength of this study was the use of two coders to increase reliability of the data. A limitation of the study is the absence of follow-up interviews to confirm whether or not the speculations about potential barriers for policy implementation became real. Future research would benefit from determining the current status of action plans to identify gaps and to better strategize subsequent phases of the agenda. Our study focused on human health given our interest in understanding community use of antibiotics and awareness about antibiotic resistance. Given that the NAP was developed on the One Health framework, with the goal of enhancing collaboration among the tripartite body, it is necessary to understand the perspectives of stakeholders from animal and environmental health divisions in future studies.

\section{CONCLUSIONS}

This stakeholder analysis demonstrates ongoing efforts to strengthen collaboration for effective implementation of the first strategic objective of the NAP, i.e., improve awareness and understanding of antimicrobial resistance through effective communication, education, and training. The Joint External Evaluation, formed under the Global Health Security Agenda, serves as an impetus to put into practice the One Health framework of enhancing cross-sectoral coordination for effective implementation of the National Action Plan on Antimicrobial Resistance. Ghana has a comprehensive policy and NAP that aligns with the objectives of the Global Action Plan. The lack of funds comprises the greatest challenge of implementation, however, the consensus observed among key stakeholders regarding the importance of educating the public on the prudent use of antibiotics, as well as the need for a tripartite collaborative effort, suggests national commitment to prioritize antibiotic-related programs.

Acknowledgements: The authors would like to thank all stakeholders who participated in the interviews, shared their expertise and perspectives on strategies for effective implementation of the National Action Plan on Antimicrobial Resistance. We are also grateful to Dr. Gloria Quansah Asare for her role in identifying stakeholders, and to Dr. Beryl Neequaye for her contributions to the data coding.

Funding: Department of Population Health \& Disease Prevention, University of California, Irvine.

Authorship contributions: TJ and OAO contributed to the conceptualization and design of the study. TJ conducted the analysis and both authors contributed to finalizing the manuscript. 
Competing interests: The authors completed the Unified Competing Interest form at www.icmje.org/coi disclosure.pdf (available upon request from the corresponding author), and declare no conflicts of interest.

\section{Correspondence to:}

Dr. Oladele A. Ogunseitan

University of California, Irvine

Anteater Instruction and Research Building

653 E Peltason Drive

Irvine, CA 92697, USA

Oladele.ogunseitan@uci.edu

This is an open-access article distributed under the terms of the Creative Commons Attribution 4.0 International License (CCBY-4.0). View this license's legal deed at http://creativecommons.org/licenses/by/4.0 and legal code at http://creativecommons.org/licenses/by/4.0/legalcode for more information. 


\section{REFERENCES}

1. Agyepong N, Govinden U, Owusu-Ofori A, Essack SY. Multidrug-resistant gram-negative bacterial infections in a teaching hospital in Ghana. Antimicrob Resist Infect Control. 2018;7(37). doi:10.1 186/s13756-018-0324-2

2. Lim C, Takahashi E, Hongsuwan M, Wuthiekanun V, Thamlikitkul V, Hinjoy S, et al. Epidemiology and burden of multidrug-resistant bacterial infection in a developing country. Elife. 2016;5. doi:10.7554/eLife.1 $\underline{8082}$

3. World Health Organization. Global Action Plan on Antimicrobial Resistance. https://www.who.int/antim icrobial-resistance/global-action-plan/en/. Accessed February 16, 2020.

4. Versporten A, Zarb P, Caniaux I, Gros MF, Drapier $\mathrm{N}$, Miller $\mathrm{M}$, et al. Antimicrobial consumption and resistance in adult hospital inpatients in 53 countries: Results of an internet-based global point prevalence survey. Lancet Glob Health. 2018;6(6):e619-e629.

5. Shallcross LJ, Davies SC. The World Health Assembly resolution on antimicrobial resistance. Journal of antimicrobial chemotherapy. 2014;69(11):2883-2885. doi:10.1093/jac/dku346

6. Kandel N, Sreedharan R, Chungong S, et al. Joint external evaluation process: Bringing multiple sectors together for global health security. The Lancet Global Health. 2017;5(9):e857-e858. doi:10.1016/s2214-109 x(17)30264-4

7. World Health Organisation. Joint external evaluation tool-second edition. IHR (2005). Monitoring and Evaluation framework. https://ww w.who.int/ihr/publications/WHO_HSE_GCR_2018_2/e n/. Accessed February 16, 2020.

8. World Health Organisation. Joint External Evaluation of IHR Core Capacities of the Republic of Ghana. https://extranet.who.int/sph/sites/default/file s/jeeta/WHO-WHE-CPI-2017.26-eng.pdf. Accessed August 24, 2018.

9. Council P. Health Professions Regulatory Bodies Act, 2013, Act 857 2017. https://www.pcghana.org/w p-content/uploads/2017/02/Health-Professions-Regul atory-Bodies-Act.pdf.

10. Talisuna A, Yahaya AA, Rajatonirina SC, Stephen M, Oke A, Mpairwe A, et al. Joint external evaluation of the International Health Regulation (2005). capacities: current status and lessons learnt in the WHO African region BMJ Global Health. 2019;4(6). do i:10.1136/bmigh-2018-001312
11. Ministry of Health. Ministry of Food and Agriculture, Ministry of Environment, Science, Technology and Innovation, Ministry of Fisheries and Aquaculture Development. Policy on Antimicrobial Use and Resistance. https://www.moh.gov.gh/wp-con tent/uploads/2018/04/AMR-POLICY-A5 09.03.2018-S igned.pdf. Accessed February 16, 2020.

12. Ministry of Health. Ministry of Food and Agriculture, Ministry of Environment, Science, Technology and Innovation, Ministry of Fisheries and Aquaculture Development. Ghana National Action Plan on Antimicrobial Resistance. https://www.moh.g ov.gh/wp-content/uploads/2018/04/NAP_FINAL_PD F_A4_19.03.2018-SIGNED-1.pdf. Accessed February 16,2020 .

13. Collignon P, McEwen S. One Health-Its Importance in Helping to Better Control Antimicrobial Resistance. Tropical Medicine and Infectious Disease. 2019;4(1):22. doi:10.3390/tropical $\underline{\operatorname{med} 4010022}$

14. Kelly TR, Machalaba C, Karesh WB, Crook PZ, Gilardi K, Nziza J, et al. Implementing One Health approaches to confront emerging and re-emerging zoonotic disease threats: Lessons from PREDICT. One Health Outlook. 2020;2(1):1-7. doi:10.1186/s42522-01 9-0007-9

15. Petrillo JE, Ogunseitan OA. Emerging issues in the environmental context of antibiotic-resistance. Environment International. 2018;116:39-42. doi:10.1 016/i.envint.2018.03.049

16. Donkor ES, Newman MJ, Yeboahâ€?Manu D. Epidemiological aspects of nonâ€?human antibiotic usage and resistance: Implications for the control of antibiotic resistance in Ghana. Tropical Medicine \& International Health. 2012;17(4):462-468. doi:10.111 1/j.1365-3156.2012.02955.x

17. Levy SB. Factors impacting on the problem of antibiotic resistance. Journal of Antimicrobial Chemotherapy. 2002;49(1):25-30. doi:10.1093/jac/4 $\underline{9.1 .25}$

18. Morens DM, Fauci AS. Emerging infectious diseases: Threats to human health and global stability. Heitman J, ed. PLoS Pathog. 2013;9(7):e1003467. doi:10.1371/journal.ppat.100346 $\underline{7}$

19. Paules CI, Marston HD, Fauci AS. Coronavirus infectionsâ€"more than just the common cold. Jama. 2020;323(8):707-708. doi:10.1001/jama.2020.0757 
20. Karesh WB, Dobson A, Lloyd-Smith JO, Lubroth J, Dixon MA, Bennett M, et al. Ecology of zoonoses: Natural and unnatural histories. The Lancet. 2012;380(9857):1936-1945. doi:10.1016/S0140-673 6(12)61678-X

21. Newman MJ, Frimpong E, Donkor ES, Opintan JA, Asamoah-Adu A. Resistance to antimicrobial drugs in Ghana. Infection and drug resistance. 2011;4(215).

22. Institute for Health Metrics and Evaluation. Ghana | Institute for Health Metrics and Evaluation. $\underline{\mathrm{h}}$ ttp://www.healthdata.org/ghana. Accessed April 9, 2020.

23. Donkor ES, Tetteh-Quarcoo PB, Nartey P, Agyeman IO. Self-medication practices with antibiotics among tertiary level students in Accra, Ghana: A cross-sectional study. Int J Environ Res Public Health. 2012;9(10):3519-3529. doi:10.3390/ijer ph9103519

24. Prigitano A, Romano L, Auxilia F, Castaldi S, Tortorano AM. Antibiotic resistance: Italian awareness survey 2016. J Infect Public Health. 2018;11(1):30-34. doi:10.1016/j.jiph.2017.02.010

25. Lv B, Zhou Z, Xu G, Yang D, Wu L, Shen Q, et al. Knowledge, attitudes and practices concerning selfmedication with antibiotics among university students in western China. Trop Med Int Health. 2014;19(7):769-779. doi:10.1111/tmi.12322

26. Friis K, Lasgaard M, Rowlands G, Osborne RH, Maindal HT. Health Literacy Mediates the Relationship Between Educational Attainment and Health Behavior: A Danish Population-Based Study. J Health Commun. 2016;21(sup2):54-60. doi:10.1080/1 0810730.2016 .1201175

27. Greenaway ES, Leon J, Baker DP. Understanding the association between maternal education and use of health services in Ghana: Exploring the role of health knowledge. J Biosoc Sci. 2012;44(6):733-747. $\underline{\mathrm{d}}$ oi:10.1017/S0021932012000041

28. Scott K, Beckham S, Gross M, Pariyo G, Rao KD, Cometto $\mathrm{G}$, et al. What do we know about community-based health worker programs? A systematic review of existing reviews on community health workers. Human resources for health. 2018;16(1). doi:10.1186/s12960-018-0304-X

29. Trickett EJ, Beehler S, Deutsch C, Green LW, Hawe $\mathrm{P}$, McLeroy $\mathrm{K}$, et al. Advancing the science of community-level interventions. American journal of public health. 2011;101(8):1410-1419. doi:10.2105/AI PH.2010.300113
30. Noy C. Sampling knowledge: The hermeneutics of snowball sampling in qualitative research. International Journal of social research methodology. 2008;11(4):327-344. doi:10.1080/13645570701401305

31. Braun V, Clarke V. Using thematic analysis in psychology. Qualitative research in psychology. 2006;3(2):77-101. doi:10.1191/1478088706qp063oa

32. Welsh E, editor Dealing with data: Using NVivo in the qualitative data analysis process. Forum qualitative sozialforschung/Forum: qualitative social research. 2002.

33. Creswell JW, Poth CN. Qualitative Inquiry and Research Design: Choosing among Five Approaches. Sage publications; 2016.

34. Bengtsson M. How to plan and perform a qualitative study using content analysis. NursingPlus Open. 2016;2:8-14. doi:10.1016/j.npls.2016.01.001

35. Ahiabu M-A, TersbÃ ll BP, Biritwum R, Bygbjerg IC, Magnussen $\mathrm{P}$. A retrospective audit of antibiotic prescriptions in primary health-care facilities in Eastern Region, Ghana. Health policy and planning. 2016;31(2):250-258. doi:10.1093/heapol/czv048

36. Dayie NT, Arhin RE, Newman MJ, Dalsgaard A, Bisgaard M, Frimodt-MÃ ller N, et al. MultidrugResistant Streptococcus pneumoniae Isolates from Healthy Ghanaian Preschool Children. Microb Drug Resist. 2015;21(6):636-642. doi:10.1089/mdr.2014.03 $\underline{14}$

37. Odonkor ST, Addo KK. Prevalence of MultidrugResistant Escherichia coli Isolated from Drinking Water Sources. Int J Microbiol. 2018;2018(7204013).

38. Comolet T. Multidrug-resistant tuberculosis: Challenges of a global emergence. Bull Soc Pathol Exot. 2015;108(4):290-298. doi:10.1007/s13149-015-0 $\underline{443-4}$

39. Ghana Statistical Service (GSS) GHSG and, International I. Education in Ghana: Data from the 2014 Ghana Demographic and Health Survey. http s://dhsprogram.com/pubs/pdf/DM87/DM87.pdf. Accessed March 6, 2020.

40. van der Heide I, Wang J, Droomers M, Spreeuwenberg P, Rademakers J, Uiters E. The relationship between health, education, and health literacy: Results from the Dutch Adult Literacy and Life Skills Survey. J Health Commun. 2013;1(Suppl 1):172-184. doi:10.1080/10810730.2013.825668 
41. Yevutsey SK, Buabeng KO, Aikins M, Anto BP, Biritwum RB, Frimodt-MÃ ller N, et al. Situational analysis of antibiotic use and resistance in Ghana: Policy and regulation. BMC Public Health. 2017;17(1):896. doi:10.1186/s12889-017-4910-7

42. Alhomoud F, Aljamea Z, Almahasnah R, Alkhalifah K, Basalelah L, Alhomoud FK. Selfmedication and self-prescription with antibiotics in the Middle Eastâ€"do they really happen? A systematic review of the prevalence, possible reasons, and outcomes. International journal of infectious diseases. 2017;57:3-12. doi:10.1016/j.ijid.2017.01.014

43. Leung E, Weil DE, Raviglione M, Nakatani H. The WHO policy package to combat antimicrobial resistance. Bulletin of the World Health Organization. 2011;89:390-392. doi:10.2471/BLT.11.088435

44. Agbo S, Gbaguidi L, Biliyar C, et al. Establishing National Multisectoral Coordination and collaboration mechanisms to prevent, detect, and respond to public health threats in Guinea, Liberia, and Sierra Leone 2016-2018. One Health Outlook. 2019;1(1). doi:10.1186/s42522-019-0004-Z
45. Robinson TP, Bu D, Carrique-Mas J, FÃ vre EM, Gilbert M, Grace D, et al. Antibiotic resistance is the quintessential One Health issue. Transactions of the Royal Society of Tropical Medicine and Hygiene. 2016;110(7):377-380. doi:10.1093/trstmh/trw048

46. Amalba A, Mohammed BS, Ameade EPK, Woode E. Stocking and dispensing of veterinary medicines by pharmacists in Ghana. Pharmacy Education. 2017;17.

47. Chapman R, Blench R, Kranjac-Berisavljevic G, Zakariah A. Rural radio in agricultural extension: The example of vernacular radio programmes on soil and water conservation in N. Ghana AgREN Network Paper. 2003;127(2).

48. Fayoyin A. Engaging Social Media for Health Communication in Africa:Approaches, Results and Lessons. J Mass Communicat Journalism. 2016;6(6). $\underline{\mathrm{d}}$ oi:10.4172/2165-7912.1000315 